\title{
KEANEKARAGAMAN ODONATA DI WADUK SELOREJO KABUPATEN MALANG DAN SUMBER CLANGAP KABUPATEN KEDIRI
}

Muhammad Azmi Dwi Susanto ${ }^{1 *}$, Muhammad Muhibbuddin Abdillah'², Zakki Mubarak ${ }^{3}$

1, 2, 3 Program Studi Biologi, UIN Sunan Ampel Surabaya, Jln. A. Yani 117, Surabaya, 60237

Indonesia

*Corresponding author, e-mail: muhammadazmidwi@gmail.com

\section{ABSTRACT}

The Selorejo Reservoir administratively is located in Malang district while Sumber Clangap is located in Kediri district. Both of these locations have different environmental conditions both abiotic and biotic components. Selorejo Reservoir has fewer tree canopies and the area dominated with herbs from Poaceae. Sumber Clangap has heterogeneous vegetation from trees, bush, and herbs. Odonata diversity at Waduk Selorejo is never been studied before while Odonata diversity data at Sumber Clangap needed an update. This study aims to determine the diversity of Odonata in Sumber Clangap and Selorejo Reservoir. The method used in this study is the transect belt and visual day flying to get the data type and number of Odonata. Data were analyzed used the Shannon-Wiener Index. Selorejo Reservoir has 75 individual that is divided into 2 families of Odonata. Sumber Clangap Have 399 individual that is divided into 5 families. The results showed that there were 17 species of Odonata included in six families in both locations. The data showed that the measured diversity by Shannon-Wiener Index at Sumber Clangap $H^{\prime}=1.81$ which is higher than the diversity of the Waduk Selorejo, $H^{\prime}=1.7$.

Keywords: Odonata Diversity, Selorejo Reservoir, Sumber Clangap

\section{PENDAHULUAN}

Odonata (capung dan capung-jarum) merupakan hewan yang masuk ke dalam Kelas Insekta. Capung masuk ke dalam Subordo Anisoptera sedangkan Capung Jarum masuk ke dalam Subordo Zygoptera. Odonata memiliki peranan dalam ekosistem sebagai predator dengan mangsa berupa serangga dari spesies lain (Setiyono et al. 2017). Insekta ini merupakan hewan perairan yang mengalami metamorfosis tidak sempurna (hemimetabola). Odonata menghabiskan fase larva (naiad) di dasar perairan sebelum berkembang ke fase dewasa (imago) (Setiyono et al. 2017). Habitat perairan dapat berupa mata air yang banyak sekali terdapat pada pegunungan di Indonesia.

Gunung Kelud merupakan gunung api aktif di tiga kabupaten di Provinsi Jawa Timur. Kawasan Gunung Kelud meliputi Kabupaten Blitar, Kediri dan Malang. Hutan di kawasan Gunung Kelud bertipe hutan hujan dataran rendah dengan topografi berbukit sangat terjal (Hadiyanti et al. 2017). Hutan tersebut selain sebagai penyedia plasma nutfah juga memiliki fungsi sebagai penyimpanan air tanah (Tarigan et al. 2018). Keberadaan hutan tersebut menjadikan Gunung Kelud memiliki beberapa mata air yang membentuk sungai. Keberadaan sungai sangat mendukung keberadaan Odonata yang merupakan hewan perairan. Selain keberadaan mata air sebagai penyedia habitat bagi naiad Odonata, hutan heterogen dengan berbagai jenis vegetasi juga merupakan faktor lain yang mendukung keberadaan Odonata (Abdillah et al. 2020)

Gunung Kelud merupakan kawasan yang mendukung keberadaan Odonata, tetapi data jenis Odonata pada wilayah tersebut belum banyak dipublikasikan. 
Kawasan Sumber Clangap dan Sumber Mangli terletak pada lereng utara Gunung Kelud ditemukan 17 spesies Odonata (Abdillah et al. 2019). Data jenis Odonata pada bagian lain dari Gunung Kelud belum pernah dipublikasi sebelumnya. Selain itu, monitoring secara periodik perlu dilakukan. Suksesi yang terus terjadi pada hutan kawasan Gunung Kelud pasca erupsi pada tahun 2014 juga akan mengubah keanekaragaman jenis dari Odonata.

Sumber Clangap dan Waduk Selorejo dipilih karena lokasi ini memiliki tipe habitat yang berbeda dimana Waduk Selorejo memiliki perairan yang lebih tenang dan terbuka dibandingkan Sumber Clangap. Data keanekaragaman jenis Odonata di Sumber Clangap terakhir pada tahun 2018, sehingga memerlukan pembaruan. Waduk Selorejo memiliki tipe lahan terbuka tanpa banyak kanopi dan air lebih tenang sehingga diharapkan memiliki spesies Odonata yang berbeda. Berdasarkan beberapa argumen tersebut, penelitian ini bertujuan untuk mengetahui keanekaragaman Odonata di kawasan Sumber Clangap dan Waduk Selorejo. Data jenis Odonata yang dikumpulkan kemudian agar dapat dimanfaatkan sebagai dasar dalam melakukan konservasi maupun pengembangan wilayah.

\section{METODE}

\section{Lokasi Studi}

Penelitian dilakukan pada bulan Januari 2019, berlokasi di Sumber Clangap Kabupaten Kediri dan Waduk Selorejo di Kabupaten Malang. Peta lokasi penelitian pada Gambar 1.

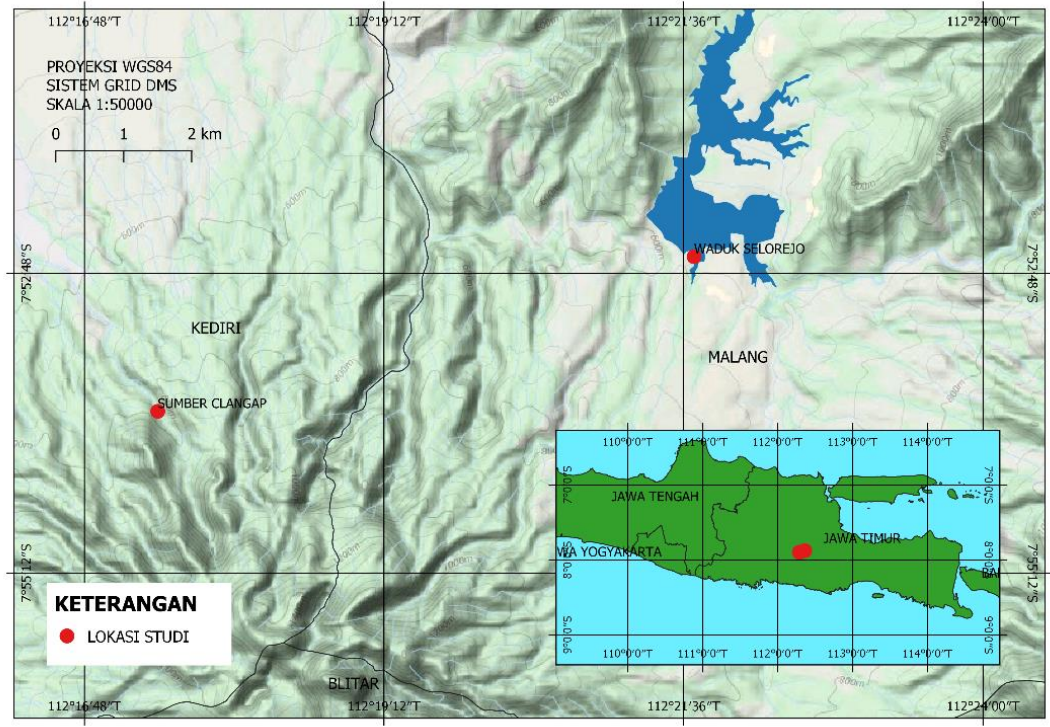

Gambar 1. Peta Penelitian (Sumber: Google Maps \& Peta Rupa Bumi Indonesia, 2020)

\section{Bahan dan Alat}

Bahan yang digunakan adalah Etanol 70\% sebanyak $100 \mathrm{ml}$. Alat yang digunakan dalam penelitian yaitu alat tulis, kamera, GPS (Global Positioning System), Thermohigrometer, Jam Tangan, Jaring Serangga

\section{Metode Pengambilan Data}

Pengambilan data menggunakan metode Visual Day Flying yang dilakukan di sepanjang transect belt yang ditentukan secara purposive berdasarkan kemudahan akses. Visual Day Flying yaitu mencatat jumlah dan jenis Odonata pada jam aktif 
terbang (08.00-15:00 WIB). Selain jumlah dan jenis, data mikro iklim seperti suhu dan kelembaban udara juga dicatat untuk keperluan analisis data. Kegiatan identifikasi dilakukan di lokasi penelitian dan dipandu buku identifikasi Orr (2005) dan Setiyono et al. (2017).

\section{Analisis Data}

Data jumlah dan jenis Odonata yang diperoleh kemudian dianalisis menggunakan Indeks Keanekaragaman Shanon-Wiener $\left(\mathrm{H}^{\prime}\right)$. Rumus yang digunakan dalam menentukan indeks keanekaragaman jenis sebagai berikut:

\section{$H^{\prime}=-\sum P i \ln (P i)$}

Keterangan:

$H^{\prime}=$ Indeks Keanekaragaman Shannon-Wienner

$P i=(n i / \mathrm{N})$

$n i=$ Jumlah individu jenis ke- $i$.

$\mathrm{N}=$ jumlah individu seluruh jenis (Kannagi et al. 2016).

\section{HASIL DAN PEMBAHASAN}

Odonata yang diperoleh dari pengambilan data di Waduk Selorejo yaitu sebanyak 7 spesies (75 individu) dari dalam 2 famili yaitu Libellulidae dan Coenagrionidae. Sedangkan di Sumber Clangap sebanyak 13 spesies (399 individu) yang terdiri dari 5 famili yaitu Euphaeaidae, Libellulidae, Gomphidae, Coenagrionidae dan Platycnemididae (Tabel 1). Spesies Odonata yang paling banyak ditemukan di kedua lokasi adalah Pantala flavescens dengan jumlah 24 individu di Waduk Selorejo dan di Sumber Clangap sebanyak 154 individu. Spesies yang paling sedikit ditemukan di Waduk Selorejo adalah Pseudagrion microchepalum dengan jumlah 2 individu dan di Sumber Clangap adalah Zygonyx ida sebanyak 2 individu.

Jenis dan jumlah individu yang ditemukan di dua lokasi berbeda karena keduanya memiliki perbedaan kondisi lingkungan (biotik dan abiotik). Komponen abiotik dapat berupa keadaan fisik habitat suhu dan kelembaban udara, intensitas cahaya serta ketersediaan air (Abdillah, 2018). Komponen biotik dalam lingkungan yang mempengaruhi keberadaan Odonata dapat berupa vegetasi yang dijadikan tempat berlindung dan sumber pakan (Abdillah et al. 2020; Hartika et al. 2017). Hasil penelitian menunjukkan adanya perbedaan spesies yang ditemukan di Sumber Clangap jika dibandingkan dengan data tahun 2018, pada tahun 2019 ditemukan Nepogomphus frushtorferi dan Diplacodes trivialis.

Indeks keanekaragaman di Waduk Selorejo adalah $\mathrm{H}^{\prime}=1,70$, sedangkan di lokasi Sumber Clangap adalah $\mathrm{H}^{\prime}=1,81$ (Gambar 2). Faktor utama yang mempengaruhi indeks keanekaragaman dari kedua lokasi adalah perbedaan kondisi fisik lingkungan, ketersediaan makanan, habitat dan sumber daya alam serta daya jelajah spesies (Herlambang et al. 2016). Perbedaan jenis vegetasi memiliki pengaruh yang besar terhadap keanekaragaman Odonata khususnya pada Famili Libellulidae yang ditemukan pada kedua lokasi (Abdillah et al. 2020). Berdasarkan data jumlah spesies dari famili Libellulidae pada Waduk Selorejo adalah 4 spesies dan Sumber Clangap sebanyak 8 spesies. Odonata dalam seleksi habitat dibantu dengan organ olfaktori yang terdapat pada antenanya. Organ tersebut membantu odonata dalam menentukan keberadaan senyawa kimia termasuk keberadaan vegetasi di habitatnya (Nugrahani et al. 2014). 
Tabel 1. Jenis Odonata di Waduk Selorejo dan Sumber Clangap

\begin{tabular}{|c|c|c|c|c|c|}
\hline \multirow{2}{*}{ Subordo } & \multirow{2}{*}{ Famili } & \multirow{2}{*}{ Spesies } & \multicolumn{2}{|c|}{ Jumlah Individu } & \multirow{2}{*}{$\begin{array}{c}\text { Status } \\
\text { Konservasi }\end{array}$} \\
\hline & & & L1 & L2 & \\
\hline \multirow[t]{7}{*}{ Zygoptera } & Calopterygidae & Vestalis luctuosa & & 72 & LC \\
\hline & Coenagrionidae & Agriocnemis femina & 7 & & LC \\
\hline & & Ishcnura senegalensis & 15 & & LC \\
\hline & & Pseudagrion pruinosum & & 13 & LC \\
\hline & & Pseudagrion microchepalum & 2 & & LC \\
\hline & Euphaeaidae & Euphaea variegata & & 76 & LC \\
\hline & Platycnemididae & Coeliccia membranipes & & 5 & LC \\
\hline \multirow[t]{10}{*}{ Anisoptera } & Gomphidae & Nepogomphus frushtorferi & & 6 & NT \\
\hline & Libellulidae & Crocothemis servilia & 8 & & LC \\
\hline & & Diplacodes trivialis & 3 & 12 & LC \\
\hline & & Neurothemis fluctuans & & 4 & LC \\
\hline & & Orthetrum glaucum & & 30 & LC \\
\hline & & Orthetrum pruinosum & & 3 & LC \\
\hline & & Orthetrum sabina & 16 & 3 & LC \\
\hline & & Pantala flavescens & 24 & 154 & LC \\
\hline & & Trithemis festiva & & 19 & LC \\
\hline & & Zygonyx ida & & 2 & LC \\
\hline Total & & & 75 & 399 & \\
\hline
\end{tabular}

Keterangan: Waduk Selorejo (L1), Sumber Clangap (L2), Sumber: (Boudot et al. 2016; Dow 2015d, 2020b, 2015c, 2015b, 2015a, 2017, 2019b, 2019a, 2019c, 2020a; Dow \& Wilson 2017; Mitra 2020; Sharma 2015; Sharma \& Clausnitzer 2016; Subramanian 2020a, 2020b).

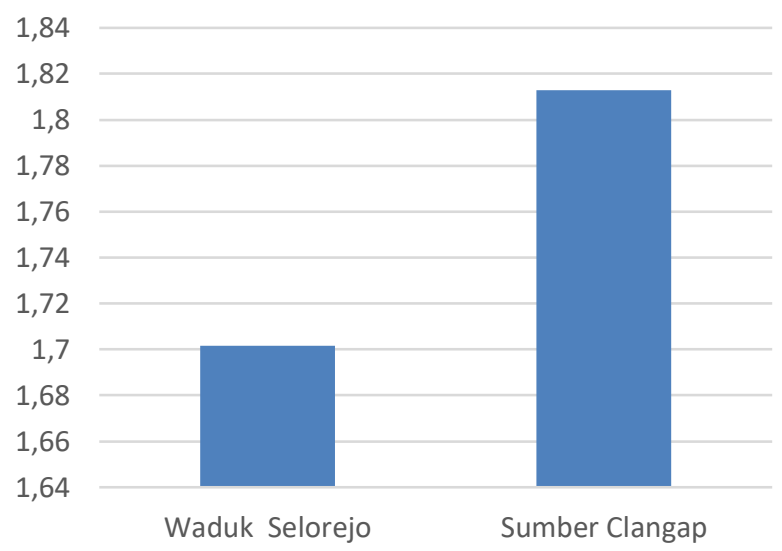

Gambar 2. Grafik Indeks Keanekaragaman

Waduk Selorejo merupakan lahan basah buatan dengan vegetasi terbuka dengan sedikit pepohonan dan terdapat banyak rerumputan di tepi waduk (Muljaningsih, 2019). Berdasarkan hasil penelitian, hanya terdapat 4 spesies Odonata dari Famili Libellulidae di Waduk Selorejo. Jumlah spesies yang lebih sedikit sangat berkaitan berkaitan dengan kondisi (keanekaragaman) vegetasi. Spesies yang masuk dalam Famili Libellulidae memerlukan vegetasi tingkatan pohon untuk menghindari pemangsa sedangkan Waduk Selorejo memiliki sedikit pepohonan (Abdillah et al. 2020). 
Sumber Clangap adalah aliran lahar dingin Gunung Kelud yang membentuk sungai. Aliran air tersebut bersumber dari hutan yang terletak di sepanjang daerah tepi sungai. Pada tahun 2018, vegetasi hampir menutupi riparian aliran Sumber Clangap dan juga menyediakan habitat bagi capung. Pohon yang terdiri dari 12 spesies pada Sumber Clangap menyediakan tempat berlindung bagi famili Libellulidae dari pemangsa (Abdillah et al. 2020).

Table 2. Parameter Abiotik di Waduk Selorejo dan Sumber Clangap

\begin{tabular}{cccc}
\hline Lokasi & Suhu $\left({ }^{\circ} \mathrm{C}\right)$ & Kelembaban Udara (\%) & Intensitas cahaya (lx) \\
\hline Waduk Selorejo & 25,9 & 82,0 & 21072 \\
Sumber Clangap & 28,6 & 84,5 & 3342 \\
\hline
\end{tabular}

Berdasarkan data parameter abiotik dan keragaman jenis terdapat beberapa faktor yang berpengaruh pada keberadaan suatu spesies. Suhu, kelembaban udara serta intensitas cahaya merupakan faktor lingkungan yang berpengaruh pada fase metamorfosis, pigmentasi sayap, adaptasi termal, perilaku kawin, perilaku bertelur dan mencari mangsa (Herlambang et al. 2016; Svensson \& Waller 2013). Keberadaan vegetasi pohon sangat berpengaruh pada suhu dan kelembaban udara pada ketinggian 2 meter di atas tanah (Procházka et al. 2011). Selain itu keberadaan vegetasi pohon dengan kanopi juga mengurangi intensitas cahaya sehingga keberadaan pohon berpengaruh pada keanekaragaman Odonata. Odonata dari Subordo Zygoptera (capung-jarum) umumnya lebih banyak ditemukan pada daerah yang ternaung kanopi dengan kelembaban yang tinggi seperti Coeliccia membranipes. Berdasarkan hasil pengamatan (Tabel 1), terdapat 3 spesies yang masuk dalam Subordo Zygoptera di Waduk Selorejo dan di Sumber Clangap sebanyak 4 spesies.

Berdasarkan data, spesies yang ditemukan pada kedua lokasi dengan jumlah terbanyak adalah Pantala flavescens. P. flavescens banyak ditemukan di daerah pertanian yang memiliki vegetasi terbuka termasuk perairan seperti Waduk Selorejo. $P$. flavescens terbang secara berkelompok dengan jumlah ratusan bahkan ribuan dan sering ditemukan hinggap pada vegetasi herba dari famili Poaceae (Kulkarni and Subramanian 2013; Setiyono et al. 2017). Jumlah terbanyak pada kedua lokasi menyebabkan $P$. flavescens dapat digunakan sebagai tolak ukur dalam membandingkan kedua lokasi penelitian. Jumlah individu sebanyak 154 pada Waduk Selorejo sedangkan pada Sumber Clangap hanya 24 individu memberikan gambaran bahwa tingginya intensitas cahaya pada Waduk Selorejo berpengaruh pada populasi spesies tersebut. $P$. flavescens tidak banyak terpengaruh oleh keberadaan vegetasi karena kemampuan migrasinya sangat tinggi. Berdasarkan uji isotop pada sayap, Pantala flavescens kemungkinan mengalami rangkaian migrasi sejauh 14.000 - 18.000 $\mathrm{km}$ (Hobson et al. 2012). P. flavescens merupakan spesies yang memiliki persebaran paling luas dibandingkan spesies odonata lain serta ditemukan sangat melimpah pada daerah tropis dengan populasi stabil (Boudot et al. 2016).

Nepogomphus frushtorferi dan Diplacodes trivialis baru ditemukan pada lokasi Sumber Clangap pada tahun 2019. N. frushtorferi memiliki tubuh berukuran kecil, biasa ditemukan di sekitar aliran sungai yang jernih di hutan pada ketinggian 100-650 mdpl, tersebar di seluruh Sundaland kecuali Kalimantan dan Lesser Sunda (Dow 2020b). Nepogomphus trivialis dalam status konservasi masuk dalam kategori Near Threatened (NT) tanpa catatan individu yang ditemukan di Pulau Jawa (Dow 2020b). Diplacodes trivialis masuk dalam kategori sangat toleran, umumnya ditemukan di tempat datar dengan banyak batu seperti Sumber Clangap (Nugrahani et al. 2014; Setiyono et al. 
2017). Diplacodes trivialis memiliki tubuh berukuran kecil dengan jantan berwarna dominan biru, spesies ini masuk dalam kategori Least Concern (LC) (Setiyono et al. 2017; Subramanian 2020a).

\section{SIMPULAN}

Odonata yang ditemukan di Waduk Selorejo sebanyak 7 spesies yang terbagi dalam 2 famili, sedangkan di Sumber Clangap sebanyak 13 spesies yang tergolong dalam 5 famili. Indeks keanekaragaman Odonata di Waduk Selorejo $\left(H^{\prime}=1,7\right)$ Sumber Clangap $\left(H^{\prime}=1,81\right)$. Terdapat catatan baru Nepogomphus frushtorferi dan Diplacodes trivialis di Sumber Clangap.

\section{UCAPAN TERIMAKASIH}

Terima kasih kepada Kelompok Studi Entomologi KUTRIK Program Studi Biologi UIN Sunan Ampel Surabaya atas bantuan tenaga dan materi.

\section{REFERENSI}

Abdillah, M. M. (2018). Diversitas Odonata dan Peranannya Sebagai Indikator Kualitas Air Di Sumber Clangap dan Sumber Mangli Desa Puncu Kecamatan Puncu Kabupaten Kediri. Skripsi. Fakultas Sains dan Teknologi, UIN Sunan Ampel.

Abdillah, M. M., Tatag B. P. P., \& Esti Tyastirin. (2019). Odonata Diversity at Sumber Clangap and Sumber Mangli Puncu Village Sub District of Puncu District of Kediri. Jurnal Biodjati 4(2), 236-43.

Abdillah, M. M., Najmatul M., Nauval A., Firdaus A., \& Widya Pertiwi. (2020). Correlation between Libellulidae Diversity and Vegetation Diversity at Sumber Clangap Village of Puncu, Subdistrict of Puncu, District of Kediri. The Proceeding of the International Symposium on Bioremediation, Biomaterial, Revegation, and Conservation.

Boudot, J. P., V. Clausnitzer, B. Samraoui, F. Suhling, K. D. B. Dijkstra, W. Schneider, \& D. R. Paulson. (2016). Pantala flavescens. The IUCN Red List of Threatened Species. http://dx.doi.org/10.2305/IUCN.UK.2016-3.RLTS.T59971A65818523.en. Retrieved May 30, 2020.

Dow, R. A. (2015a). Orthetrum glaucum. The IUCN Red List of Threatened Species. http://dx.doi.org/10.2305/IUCN.UK.2009-2.RLTS.T163780A5650496.en Retrieved May 30, 2020.

Dow, R. A. (2015b). Pseudagrion pruinosum. The IUCN Red List of Threatened Species. https://dx.doi.org/10.2305/IUCN.UK.2020-1.RLTS.T167212A138284491.en Retrieved May 30, 2020.

Dow, R. A. (2015c). Trithemis festiva. The IUCN Red List of Threatened Species. http://dx.doi.org/10.2305/IUCN.UK.2009-2.RLTS.T163609A5623492.en. Retrieved May 30, 2020

Dow, R. A. (2015d). Zygonyx ida. The IUCN Red List of Threatened Species. http://dx.doi.org/10.2305/IUCN.UK.2011-2.RLTS.T190852A8836773.en Retrieved May 30, 2020.

Dow, R. A. (2017). Crocothemis servilia. The IUCN Red List of Threatened Species. http://dx.doi.org/10.2305/IUCN.UK.2017-3.RLTS.T163607A80679957.en Retrieved May 30, 2020.

Dow, R. A. (2019a). Coeliccia membranipes. The IUCN Red List of Threatened Species. https://dx.doi.org/10.2305/IUCN.UK.2019-2.RLTS.T122883843A123029783.en. 
Retrieved May 30, 2020.

Dow, R. A. (2019b). Euphaea variegata. The IUCN Red List of Threatened Species. http://dx.doi.org/10.2305/IUCN.UK.2019- 2.RLTS.T122209669A122209989.en. Retrieved May 30, 2020.

Dow, R. A. (2019c). Vestalis luctuosa. The IUCN Red List of Threatened Species. http://dx.doi.org/10.2305/IUCN.UK.2019-3.RLTS.T163807A137392306.en Retrieved May 30, 2020.

Dow, R. A. (2020a). Agriocnemis femina. The IUCN Red List of Threatened Species. https://dx.doi.org/10.2305/IUCN.UK.2020-1.RLTS.T167208A83375055.en Retrieved May 30, 2020.

Dow, R. A. (2020b). Nepogomphus fruhstorferi. The IUCN Red List of Threatened Species. https://dx.doi.org/10.2305/IUCN.UK.2020- 1.RLTS.T139369530A139404028.en .Retrieved May 30, 2020.

Dow, R. A., \& K. D. P. Wilson. (2017). Pseudagrion microcephalum. The IUCN Red List of Threatened Species. https://dx.doi.org/10.2305/IUCN.UK.20171.RLTS.T167199A83376119.en. Retrieved May 30, 2020

Hartika, W., Farah D, \& Wahdina. (2017). Keanekaragaman Jenis Capung (Odonata) Pada Ruang Terbuka Hijau Kota Pontianak. Jurnal Hutan Lestari, 5 (2), 156-163.

Hadiyanti, N., Pardono, Supriyadi. (2017). Kerapatan dan Sifat Morfologi Ciplukan (Physalis sp.) di Gunung Kelud, Jawa Timur. Jurnal Hijau Cendekia 2(2), 71-77

Herlambang, A. E. N., Mochamad H. \& Udi T. (2016). Struktur Komunitas Capung Di Kawasan Wisata Curug Lawe Benowo Ungaran Barat. Bioma: Berkala Ilmiah Biologi, 18(2), 70-78

Hobson, K. A., R., Charles A., David X. S., \& Leonard I. W. (2012). Isotopic Evidence That Dragonflies (Pantala Flavescens) Migrating through the Maldives Come from the Northern Indian Subcontinent. PLoS ONE, 7(12), 9-12.

Kannagi, A., V. Sivakumar \& V. Santhi. (2016). Diversity of Dragonflies (Insecta: Odonata) in a Deciduous Forest of Thoothukudi District, Tamil Nadu, South India. International Journal of Environmental Protection and Policy, 4(3), 58-63.

Kulkarni, A. S. \&K. A. Subramanian. (2013). Habitat and Seasonal Distribution of Odonata (Insecta) of Mula and Mutha River Basins, Maharashtra, India. Journal of Threatened Taxa, 5(7), 4084-95.

Mitra, A. (2020). Orthetrum sabina. The IUCN Red List of Threatened Species. https://dx.doi.org/10.2305/IUCN.UK.2020-1.RLTS.T165470A83377025.en.

Retrieved May 30, 2020

Muljaningsih, S. (2019). Pengembangan Waduk Selorejo Berkelanjutan : Perspektif. 4 pp. 335-40 in Prosiding Seminar Nasional Lingkungan Lahan Basah, Universitas Lambung Mangkurat.

Nugrahani, M., L. Nazar, Tabita M., \& Joko Setiyono. (2014). Peluit Tanda Bahaya: Capung Indikator Lingkungan Panduan Penilaian Kualitas Lingkungan Melalui Capung. Yogyakarta: Indonesian Dragonflies Society.

Orr, A. G. (2005). Dragonflies of Peninsular Malaysia and Singapore. Kinabalu: Natural History Publication.

Procházka, J., Jakub B., Jakub Š., \& Emilie P. (2011). The Impact of Vegetation Cover on Temperature and Humidity Properties in the Reclaimed Area of a Brown Coal Dump. International Journal of Mining, Reclamation and Environment 25(4), 35066.

Setiyono, J., Siti D., Nurdin S. B. \& Elde N. R. O. (2017). Dragonflies of Yogyakarta. Yogyakarta: Indonesian Dragonflies Society. 
Sharma, G. (2015). Orthetrum pruinosum. The IUCN Red List of Threatened Species. http://dx.doi.org/10.2305/IUCN.UK.2010-4.RLTS.T167097A6301540.en Retrieved May 30, 2020.

Sharma, G. \& V. Clausnitzer. (2016). Ischnura senegalensis. The IUCN Red List of Threatened Species. https://dx.doi.org/10.2305/IUCN.UK.20163.RLTS.T59897A75436136.en. Retrieved May 30, 2020.

Subramanian, K. A. (2020a). Diplacodes trivialis. The IUCN Red List of Threatened Species. https://dx.doi.org/10.2305/IUCN.UK.20201.RLTS.T167372A83371487.en. Retrieved May 30, 2020

Subramanian, K. A. (2020b). Neurothemis fluctuans. The IUCN Red List of Threatened Species. https://dx.doi.org/10.2305/IUCN.UK.20201.RLTS.T167488A83383506.en. Retrieved May 30, 2020

Svensson, E. I. \& John T. W. (2013). Ecology and Sexual Selection: Evolution of Wing Pigmentation in Calopterygidae Damselflies in Relation to Latitude, Sexual Dimorphism, and Speciation. American Naturalist, 182(5), 174-195

Tarigan, S, Kerstin W, Sunarti, \& Bejo S. (2018). Minimum Forest Cover Required for Sustainable Water Flow Regulation of a Watershed: A Case Study in Jambi Province, Indonesia. Hydrology \& Earth System Sciences, 22(1), 581-94. 